\title{
Modelo de administración tributaria para optimizar la recaudación de los ingresos del gobierno autónomo descentralizado del cantón Jipijapa
}

\section{Tax administration model to optimize the collection of revenues of the decentralized Jipijapa autonomous government}

\author{
MSc, Cantos Figueroa Mariana de Lourdes ${ }^{1}$ \\ macafi1@yahoo.com \\ MSc, Baque Morán Amparo Bienvenida ${ }^{1}$ \\ amparo.baque@unesum.edu.ec \\ MSc, Jaime Baque Miguel Ángel ${ }^{1}$ \\ angel.m.86@hotmail.com \\ MSc, Ayón Ponce Gino Iván \\ ginoayon1@hotmail.com \\ MSc, Delgado Gutiérrez Zoila Mariana \\ zoila.delgado@unesum.edu.ec
}

Recibido: 1/04/2018, Aceptado: 1/06/2018

\begin{abstract}
RESUMEN
El presente trabajo de investigación se basó en la problemática de la baja recaudación de ingresos por concepto de impuestos. La metodología que se utilizó fueron los métodos de investigación teórica, como el histórico lógico, análisis documental y el sistémico estructural. Además, el método empírico estuvo basado en la observación científica, mediante la aplicación de las técnicas de la encuesta, realizada a los usuarios y entrevistas a los funcionarios del GAD cantonal, Los resultados obtenidos en todo el proceso investigativo, es la falta de una cultura de pago de impuestos por parte de la ciudadanía. Deficiente actualización de las ordenanzas municipales y normas tributarias en la recaudación de ingresos. Desde este punto de vista obtuvo la propuesta del diseñó un Modelo de Administración que tiene por finalidad organizar y ejecutar la administración y recaudación de todos los ingresos tributarios y no tributarios del Gobierno Autónomo Descentralizado Municipal del Cantón Jipijapa.
\end{abstract}

Palabras clave: impuestos, tributación, ordenanzas, gestión, administración

1 Universidad Estatal del Sur de Manabí, Ecuador 


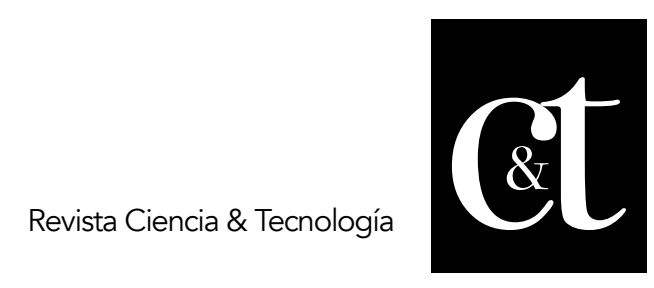

No. 19, 31 de julio de 2018

ISSN impreso: 1390 - 6321

\begin{abstract}
The present research work was based on the problem of low revenue collection due to taxes. The methodology used was theoretical research methods, such as logical history, documentary analysis and the structural system. In addition, the empirical method was based on scientific observation, through the application of survey techniques, made to users and interviews with officials of the cantonal GAD. The results obtained throughout the research process, is the lack of a culture of payment of taxes by the citizens. Poor updating of municipal ordinances and tax regulations in revenue collection. From this point of view, he obtained the proposal of designing an Administration Model that aims to organize and execute the administration and collection of all tax and non-tax revenues of the Municipal Autonomous Decentralized Government of the Jipijapa Canton.
\end{abstract}

Keywords: taxes, taxation, ordinances, management, administration

\title{
Introducción
}

La Constitución del Ecuador establece que las Municipalidades son instituciones autónomas y que actúan por delegación del Estado, cuyo fin supremo es la realización del bien común de sus habitantes. Por lo tanto, a los Gobiernos Autónomos Descentralizados se les plantea el reto de mejorar la capacidad administrativa y gerencial de sus Municipalidades para que se cumplan a cabalidad con las funciones que les asignan la Constitución de la República, el Código Orgánico de Organización Territorial Autonomía y Descentralización.

Acorde con los cambios tecnológicos ocurridos en los últimos tiempos, se ha visto en la necesidad de adoptar técnicas y métodos recientes que proporcionen un mejor fundamento de procedimientos catastrales para el estado donde corresponde determinar las bases generales técnicas y administrativas aplicables, normas, leyes y reglamentos del territorio nacional ecuatoriano.

En la actualidad se puede afirmar que los tributos se han convertido en el principal rubro del presupuesto general del estado en el caso de los tributos nacionales y lo correspondiente a los gobiernos autónomos descentralizados, en este contexto la Republica de Ecuador ha impulsado la Ley Orgánica de Régimen Municipal COOTAC, promover la descentralización y autonomía de los gobiernos autónomos.

\section{Desarrollo}

El Gobierno Autónomo Descentralizado (GAD) Municipal del Cantón Jipijapa, no cuenta con un sistema adecuado para la recaudación de ingresos tributarios y no tributarios, debido a las limitaciones en el funcionamiento del área de tesorería municipal; además de ello se puede observar que las ordenanzas municipales que datan desde 1995 a la fecha, no ha sido actualizado. Por ello, es que se diseña un modelo de administración tributaria acorde los requerimientos de las coyunturas actuales, el cual contribuye a ser más eficiente en la recaudación de ingresos para el área de tesorería que en la actualidad es limitado, siendo un problema frecuente 


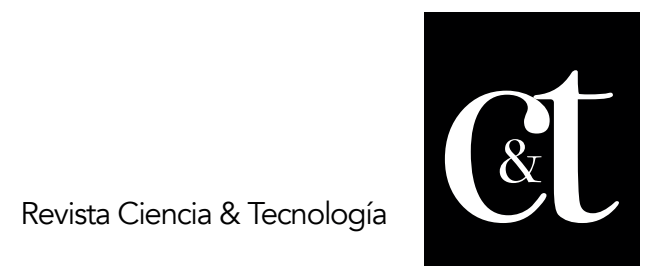

No. 19, 31 de julio de 2018

ISSN impreso: 1390 - 6321

y de gran magnitud afectando de manera significativa a la municipalidad, ya que sin estos recursos económicos la institución no puede realizar sus actividades de una manera idónea, desde este punto de vista el modelo de administración tributaria reemplaza al área de tesorería y que se constituye en una pieza fundamental para mejorar los estándares actuales que posee la municipalidad de Jipijapa.

Cabe mencionar, que en el mejor de los casos existiendo una buena recaudación, la misma se constituiría en una fuente que coadyuvaría a solventar las inversiones del GAD Municipal, ya que el tema de recaudaciones, a más de ser complejo, es una labor de perseverancia, sacrificio y continuidad, que exige en determinados momentos tomar decisiones sumamente drásticas por parte de los funcionarios involucrados en el mejoramiento y aplicabilidad de la gestión municipal.

\section{Administración tributaria}

Los impuestos nacen como un mecanismo de búsqueda de nuevos ingresos. Fueron implementados por los Estados para financiar la satisfacción de las necesidades públicas. En este sentido, se puede afirmar que los primeros recursos tributarios fueron aquellos que el Estado obtuvo mediante el ejercicio de su poder imperio o a través de costumbres que luego se convirtieron en leyes, en la Roma antigua. El origen de los tributos se remonta a la era primitiva, cuando los hombres entregaban ofrendas a los dioses a cambio de algunos beneficios. Posteriormente, desde la civilización griega, se manejaba el término de la progresividad en el pago de los impuestos por medio del cual se ajustaban los tributos de acuerdo a las capacidades de pago de las personas. También se controló su administración y su clasificación.

Igualmente, en América, culturas indígenas como la Inca, Azteca y Chibcha, pagaban los tributos de manera justa por medio de un sistema de aportes bien organizado. En la época del Imperio Romano, el Emperador Constantino extiende los impuestos a todas las ciudades incorporadas.

En Europa, durante la Edad Media, los tributos los cancelaban los pobladores en especies a los señores feudales, con los vegetales o animales que crecían en las pequeñas granjas o aldeas. A principios del siglo pasado los sistemas tributarios, tanto de los países desarrollados como subdesarrollados, estaban dominados casi exclusivamente por impuestos sobre el comercio internacional.

Sin embargo, la caída de la demanda internacional de productos primarios durante la Gran Depresión de los años 30, los altos niveles de concentración de la riqueza y los esquemas proteccionistas de industrialización por sustitución de importaciones que se implementaron en varios países de la región obligaron la introducción de reformas para incrementar el nivel de los recursos fiscales (Cornia, Gómez y Martorano, 2011).

A comienzos de la década del 80 , la "revolución neoliberal de la política fiscal" 


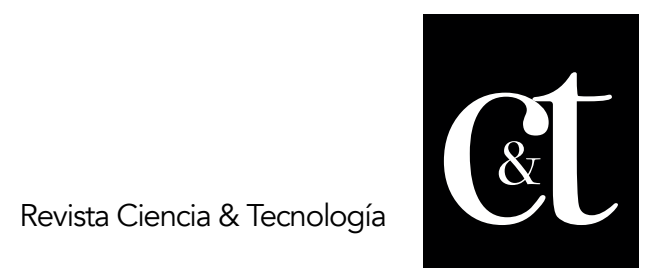

No. 19, 31 de julio de 2018

ISSN impreso: 1390 - 6321

(Jenkins, 1995) implicó un cambio en los objetivos principales que guiaron a la política tributaria en los años subsiguientes: en detrimento del objetivo redistributivo, el énfasis del diseño tributario estuvo puesto en la eficiencia, la equidad horizontal y la adecuación de los ingresos tributarios. Siguiendo fielmente las recomendaciones en la materia de organismos internacionales como el Banco Mundial y el Fondo Monetario Internacional, los hacedores de política tributaria en América Latina promovieron una fuerte reducción en las alícuotas (Lora, 2007), de los impuestos al comercio internacional (vistos como fuente de ineficiencias en la producción local y en la asignación internacional de recursos), la introducción del Impuesto al Valor Agregado, la reducción en los valores y la cantidad de alícuotas del Impuesto sobre la Renta de personas naturales, la reducción sustancial del número de tributos vigentes (eliminando la mayoría cuya contribución a la recaudación era insignificante) y la ampliación de las bases tributarias para mejorar la equidad horizontal de los sistemas tributarios de la región (Mahon, 2004).

En algunos países de la región, el aumento de la carga tributaria se explica, además, por factores contingentes como i) el sostenido aumento del precio internacional de los commodities y minerales entre 2002 y 2009, que ha incrementado los ingresos fiscales (siendo una parte de ellos de carácter tributario, según el caso) en aquellos países de la región especializados en la explotación y comercialización de sus recursos naturales (lo cual se analizará más adelante en este informe), y ii) un contexto internacional caracterizado por la aceleración en las tasas de crecimiento económico mundial (sobre todo, de los países emergentes desde 2002/03), lo cual fue aprovechado por los países de la región a través de estrategias de apertura comercial y financiera junto con exitosos procesos de estabilización monetaria, observándose un aumento en la elasticidad tributaria (ex post) de los países de América Latina (Cornia, Gómez y Martorano, 2011).

Un elemento adicional que permitió que una mayor presión tributaria fuera aceptable para muchos consistió en el mayor énfasis puesto en los últimos años en el criterio de "reciprocidad fiscal" (fiscal exchange), a través del cual los gobiernos pueden aumentar los impuestos si, respetando un pacto fiscal con los ciudadanos (CEPAL, 2010), procuran al mismo tiempo aumentar la cantidad y calidad de los servicios sociales que brindan a la sociedad (Fjeldstad et al, 2009). Como bien ha señalado (Bird, 2003): "en un marco democrático (Wickselliano) en el que las decisiones de gasto y de impuestos se toman conjuntamente... la estructura tributaria existente, cualquiera que sea, deberá suponerse que ha sido establecida con pleno conocimiento de sus consecuencias, lo que refleja el consentimiento de la sociedad en cuanto a que los beneficios de las acciones financiadas por el Estado más que compensan todos los costos de la tributación".

\section{Gestión Administrativa}

"Se la entiende como se organizan y combinan los recursos de una organización, con el propósito de cumplir las políticas, objetivos y regulaciones jurídicas, la gestión comenzó a ser usada como antónimo de administración, inspirando a la 
corriente anglosajona de la nueva gestión pública" (Guerrero, 2001).

"La Carta Magna indica que las instituciones del Estado, sus organismos, dependencias, las servidoras o servidores públicos y las personas que actúen en virtud de una potestad estatal ejercerán solamente las competencias y facultades que les sean atribuidas en la Constitución y la Ley, tendrán el deber de coordinar acciones en el cumplimiento de sus fines y hacer efectivo el goce y ejercicio de sus derechos reconocidos en la Constitución. (Asamblea Nacional, 2008, Constitución República del Ecuador. Art. 228).

"El Plan Nacional del Desarrollo es el instrumento al que se sujetarán las políticas, programas y proyectos públicos, la programación y ejecución del presupuesto del estado; y la inversión y asignación de los recursos públicos su observancia es de carácter obligatorio para el sector público e indicativo para los demás sectores." (Senplades, 2017).

Administración Pública es un término de límites imprecisos que comprende el conjunto de organizaciones públicas que realizan la función administrativa y de gestión del Estado y de otros entes públicos con personalidad jurídica, ya sean de ámbito regional o local (Diez, 1997).

Por su función, la Administración Pública pone en contacto directo a la ciudadanía con el poder político, satisfaciendo los intereses públicos de forma inmediata, por contraste con los poderes legislativo y judicial, que lo hacen de forma mediata.

Se encuentra principalmente regulada por el poder ejecutivo y los organismos que están en contacto permanente con el mismo. Por excepción, algunas dependencias del poder legislativo integran la noción de "Administración Pública" (como las empresas estatales), a la vez que pueden existir juegos de "Administración General" en los otros poderes o en organismos estatales que pueden depender de alguno.

\section{Cultura tributaria}

Brewer y González (2005) plantean que durante mucho tiempo no ha existido en Ecuador una cultura tributaria, especialmente en el nivel local, lo que es lamentable para nuestro país, ya que la política fiscal ha sido mal llevada, planteada y ejecutada a lo largo de muchos períodos de gobiernos. En repuesta a esto se ha intentado aplicar varias medidas, pero han perdido su efecto por falta de continuidad en las políticas aplicadas y los cambios efectuados a los planes económicos por los mismos gobiernos; con ello, sólo se logra un sistema inestable que no es capaz de asimilar un lineamiento en los sistemas y políticas inicialmente orientadas hacia un determinado fin. En segundo lugar, por carecer de un planteamiento orientado a controlar el gasto público, a través del mejoramiento del sector público y crear a su vez un sistema tributario firme; luego poder lograr la reactivación económica que tanto se necesita en Ecuador, es por tal motivo que se propone entonces una gestión municipal para aumentar la recaudación y evitar la 
evasión. Así como también la aplicación de instrumentos que permitan reducir el déficit fiscal.

\section{Gobierno Autónomo Descentralizado}

Los Gobiernos Autónomos Descentralizados son entidades que tienen autonomía política, administrativa financiera, los cuales se rigen bajo los principios de solidaridad, subsidiariedad, equidad interterritorial, integración y participación ciudadana.

Los GADS, son las juntas parroquiales rurales, los concejos municipales, los concejos metropolitanos, los consejos provinciales y los consejos regionales, quienes deben regirse a la ley con la finalidad del buen vivir de todo el país. La Constitución establece que los Gobiernos Autónomos Descentralizados, tienen autonomía financiera, expresada en el derecho de recibir de manera directa, predecible, oportuna, automática y sin condiciones los recursos que les corresponden de su participación en el Presupuesto General del Estado, así como en la capacidad de generar y administrar sus propios recursos de acuerdo a lo dispuesto en la Constitución y la ley.

Históricamente en nuestro país los gobiernos municipales y provinciales han tenido poco incentivos para la generación de sus propios recursos puesto que no incorporan un criterio de esfuerzo fiscal, que les permita generar sus propios recursos. A continuación, presentamos un estudio realizado por la Gerencia de Asistencia Técnica del Banco del Estado, que nos muestra la inversión en obras públicas vs el ingreso de los municipios por recaudación del tributo contribución especial de mejoras.

\section{Modelo de Administración Tributaria}

El nuevo Modelo de Administración Tributaria para el Gobierno Autónomo Descentralizado Municipal del Cantón Jipijapa se basa en la creación de un organismo público descentralizado con autonomía administrativa económica y financiera denominado Servicio de Administración Tributaria que tendría por finalidad organizar y ejecutar la administración, fiscalización y recaudación de todos los ingresos tributarios y no tributarios de la Municipalidad de Jipijapa.

Para su creación se requiere de una Ordenanza Municipal de Creación del Servicio de Administración Tributaria de la Municipalidad de Jipijapa, y su respectivo Estatuto el deberá ser aprobado mediante Decreto de Alcaldía.

La aplicación de leyes y normativas, como las ordenanzas municipales constituyen una acción de servicio a la comunidad, el mismo que genera un crecimiento y desarrollo sostenido de equilibrio social a otorgar servicios básicos y de desarrollo medio ambiental a la comunidad. La estabilidad y desarrollo, como las acciones del buen vivir, son propias del sustento de la comunidad, así el pago de impuestos y contribuciones establecidas por la ley, son elementos sustenta torios de reinversión 


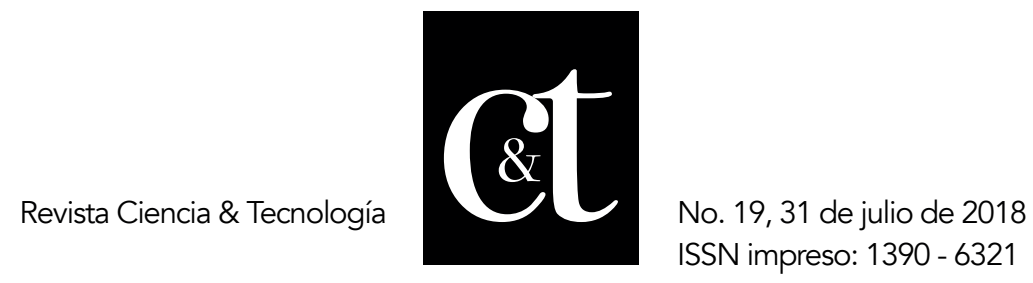

de dicha estabilidad y desarrollo del buen vivir.

El servicio público contempla el mejoramiento de la calidad de vida de las personas como lo expresa la Constitución Política del Estado, porque al recuperar valores económicos para ser invertidos en obras y acciones que beneficie a la comunidad, ya que de lo planificado se logra mejorar el entorno o medio ambiente, para que la entidad pueda cumplir las funciones, tales como:

- Dotación y mantenimiento de sistema de agua potable y alcantarillado

- Construcción, mantenimiento, aseo, embellecimiento, y reglamento del uso de caminos, calles, parques, plazas y demás espacios públicos

- Recolección, procesamiento de los residuos

- Dotación del servicio público

- Mejoramiento de aulas escolares, espacios deportivos, etc.
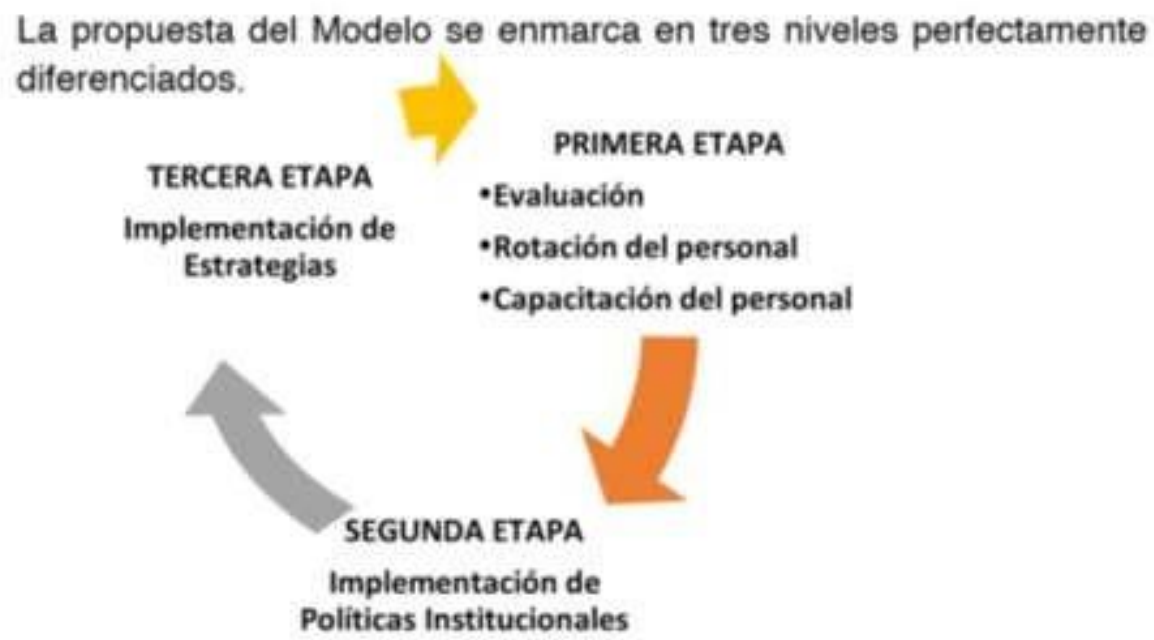

Figura 1. Plan Operativo del Modelo de Administración Tributaria Elaborado: Grupo Investigador

Primera Etapa. - Evaluación, Rotación del personal y Capacitación del personal de acuerdo a las necesidades del Gobierno Autónomo Descentralizado Municipal del Cantón Jipijapa.

Segunda Etapa. - Implementación de Políticas Institucionales que garanticen las condiciones necesarias para aplicar estrategias que mejoren la recaudación tributaria de los Impuestos Prediales.

Tercera Etapa. - Implementación de Estrategias que permitan mejorar la recaudación tributaria en el Gobierno Autónomo Descentralizado Municipal del 
Cantón Jipijapa. La propuesta se basa en la aplicación de los pasos que se definen a continuación.

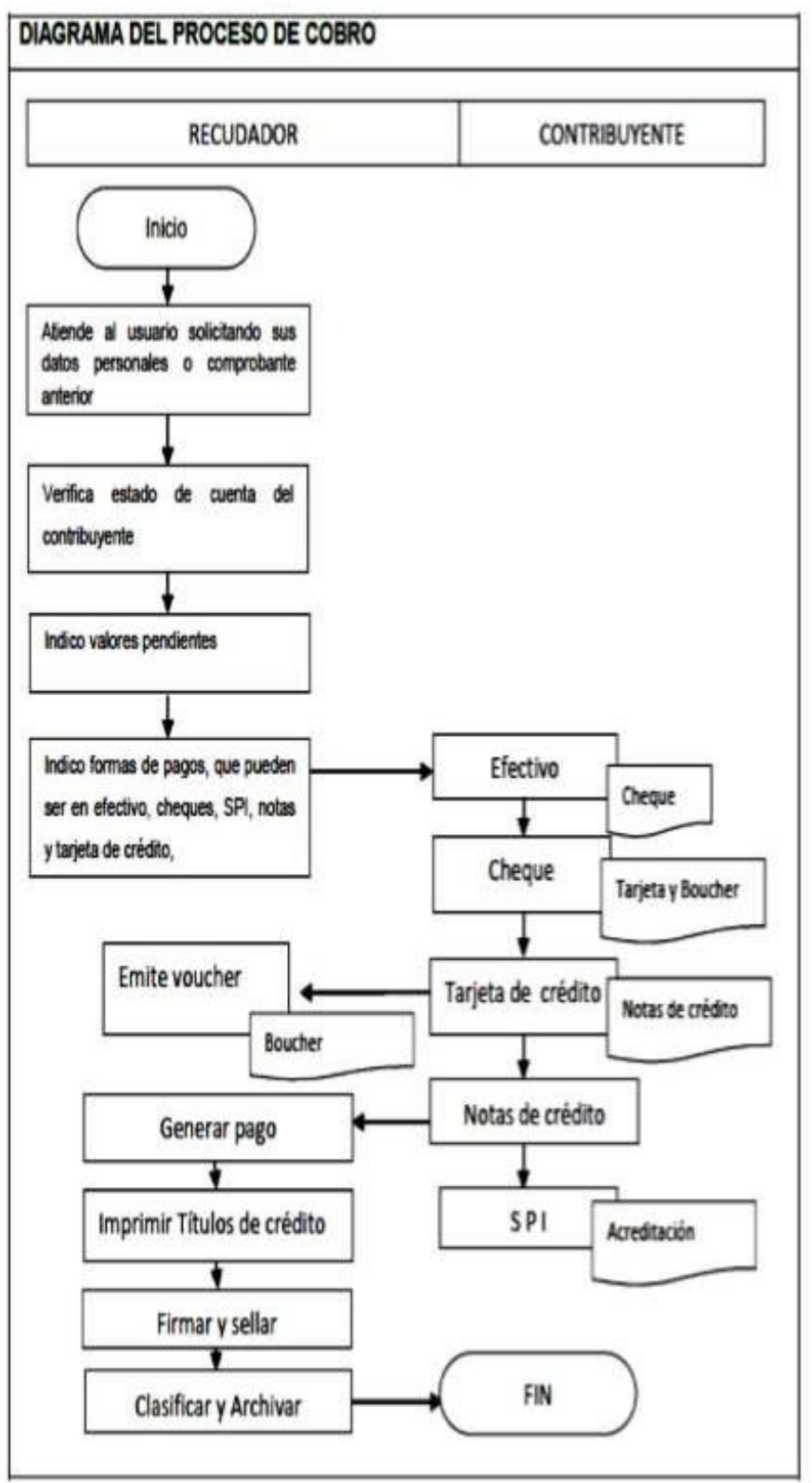

Figura 2. Diagrama del proceso de cobro Elaborado: Grupo Investigador 


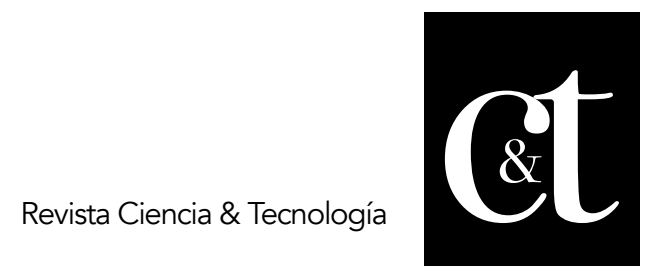

No. 19, 31 de julio de 2018

ISSN impreso: 1390 - 6321

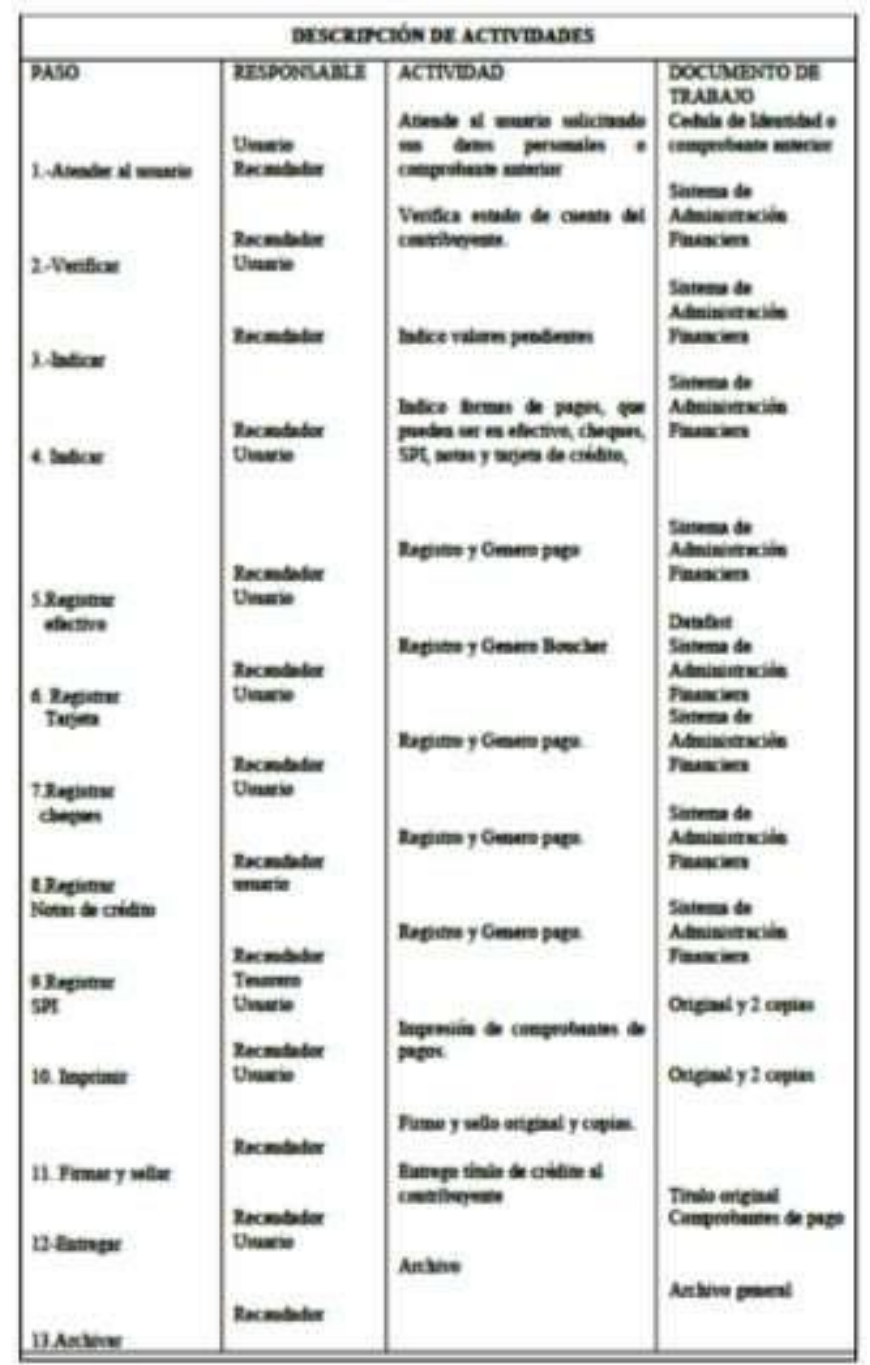

Figura 3. Actividad de cobro

Elaborado: Grupo Investigador

\section{Metodología}

La metodología que se utilizó fueron los métodos de investigación teórica, como el histórico lógico, análisis documental y el sistémico estructural. Además, el método empírico estuvo basado en la observación directa.

Estos métodos sirvieron para estudiar integralmente todos y cada uno de los procesos administrativos y funcionales del Gobierno Autónomo Descentralizado del 
cantón Jipijapa. En base a los métodos se pudo determinar los resultados y hacer la respectiva interpretación de la realidad de la problemática, mediante la técnica de la encuesta que se realizó a los ciudadanos contribuyentes donde de extrajo conclusiones relevantes para comprobar las hipótesis y la entrevista a las autoridades del Gobierno Autónomo Descentralizado del cantón Jipijapa, resultados muy valiosos que sirvieron para diseñar la propuesta sobre el Modelo de Administración Tributaria, cuya finalidad es organizar y ejecutar la administración, fiscalización y recaudación de todos los ingresos tributarios y no tributarios de la Municipalidad de Jipijapa.

\section{Resultados}

Los resultados son presentados en cuadros y gráficos de la encuesta aplicada a 378 ciudadanos contribuyentes del Cantón Jipijapa.

¿Cumple con sus obligaciones tributarias?

\section{Tabla 1. Obligaciones tributarias}

\begin{tabular}{lll}
\hline Alternativa & Frecuencia & Porcentaje \\
\hline Si & 152 & $40,2 \%$ \\
No & 226 & $59,8 \%$ \\
Total & $\mathbf{3 7 8}$ & $\mathbf{1 0 0 , 0} \%$ \\
\hline
\end{tabular}

Fuente: Usuarios de servicios del GAD - Jipijapa

Elaborado por: Investigadoree

\section{GRÁFICO Nº3 Obligaciones tributarias}

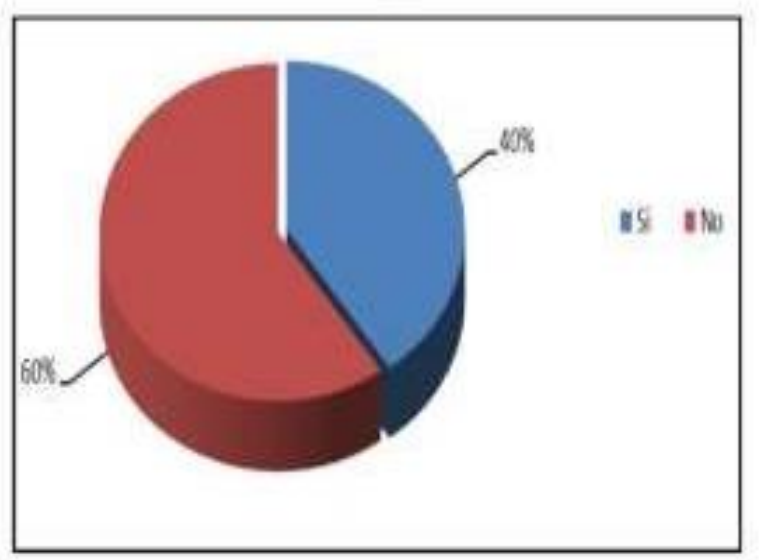


De acuerdo a los resultados obtenidos se pudo determinar que el $60 \%$ de las personas encuestadas no cumplen con sus obligaciones tributarias y el $40 \%$ de la población si cumple con sus respectivas obligaciones tributarias. Desde esta perspectiva se evidenció que en su mayoría que no están cumpliendo con el pago de los tributos para cumplir con las necesidades de obras y servicios que va en beneficios del cantón.

¿Conoce la normativa de recaudación de impuestos en Jipijapa?

Tabla 2. Conocimiento sobre normativa de recaudación

\begin{tabular}{lcc}
\hline Alternativa & Frecuencia & Porcentaje \\
\hline Si & 82 & $21,7 \%$ \\
No & 296 & $78,3 \%$ \\
Total & 378 & $100,0 \%$ \\
\hline
\end{tabular}

Fuente: Usuarios de servieios del GAD - Jipijapa

Elaborado por: Inveatigadorea

\section{GRAFICO $\mathrm{N}^{\circ} 04$ Conocimiento sobre normativa de recaudación}

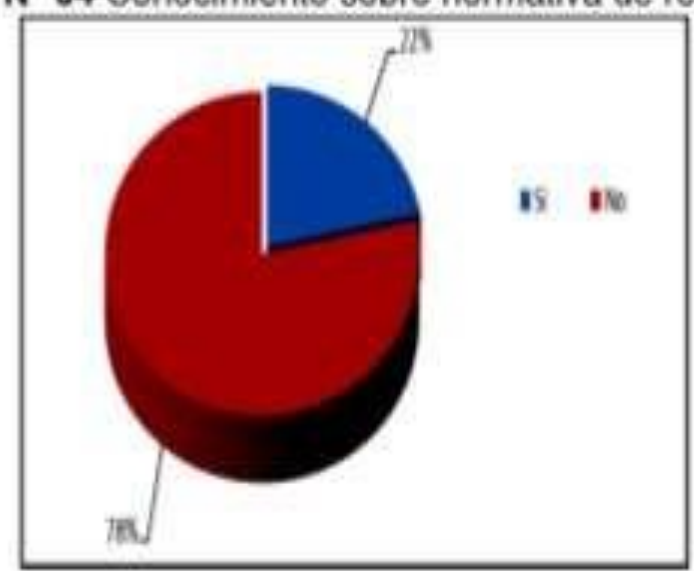

Los siguientes datos arrojados por la encuesta realizada a la ciudadanía contribuyente si conocen las normativas de recaudación de impuestos en Jipijapa, nos dicen el $78 \%$ de los encuestados que no conocen la normativa de impuestos y el $22 \%$ de los encuestados si conocen la normativa de recaudación. De los resultados se aprecia que los contribuyentes no tienen conocimientos de las normativas de recaudación que aplica el Gobierno Autónomo Descentralizado del cantón Jipijapa. Por lo tanto, es importante una concienciación a la ciudadanía para que cumplan con sus obligaciones del pago de impuesto que va en beneficios del 
cantón.

¿Está usted de acuerdo con la normativa de recaudación de impuestos en Jipijapa?

Tabla 3. De acuerdo con la normativa de recaudación de impuesto

\begin{tabular}{|lcc|}
\hline Alternativa & Frecuencia & Porcentaje \\
\hline Si & 84 & $22,2 \%$ \\
NO & 294 & $77,8 \%$ \\
Total & 378 & $100,0 \%$ \\
\hline
\end{tabular}

Fuente: Usuarioe de servieios del GAD - Jipliapa

Elaborado por: Inveetigadorea

\section{GRAFICO $N^{\circ} 05$ De acuerdo con la normativa de recaudación de impuesto}

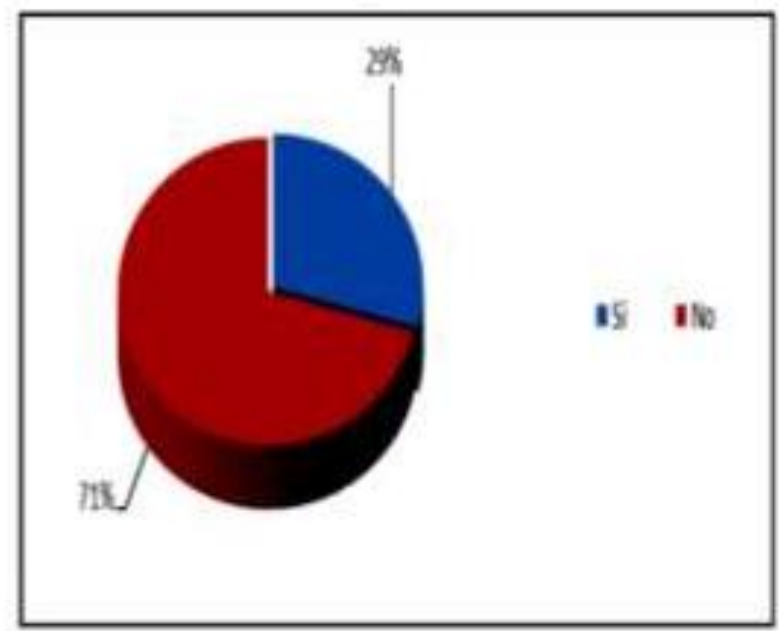

De los 378 encuestados que se les pregunto si están de acuerdo con la normativa de recaudación de impuestos en Jipijapa, el $79 \%$ no están de acuerdo con la normativa de recaudación y un $21 \%$ se encuentran de acuerdo. Estos resultados demuestran que la ciudadanía no está aportando con el pago de sus impuestos, por el desconocimiento de sus obligaciones como ciudadano y como estos tributos aportan al desarrollo de un cantón o país.

En la entrevista aplicada a las autoridades del Gobierno Autónomo Descentralizado del cantón de Jipijapa se obtuvo los siguientes resultados. 
¿Conoce las ordenanzas municipales sobre recaudación de ingresos tributarios y no tributarios?

Las autoridades a pesar del conocimiento de la importancia de recordación tributaria no conocen las ordenanzas municipales sobre recaudación de ingresos, salvo el jefe de finanzas y el tesorero, quienes por ser del área si conocen las ordenanzas.

¿Las ordenanzas municipales sobre recaudación de ingresos tributarios y no tributarios están actualizadas?

Con esta pregunta se constató por parte de las autoridades que las ordenanzas municipales sobre recaudación de ingresos no están actualizadas, manifestaron además que las pocas normas que existen datan del año 1995. Así mismo se evidenció que la moneda bajo la cual están normados es el sucre, sin embargo, a partir del año 2000 rige el dólar como moneda nacional.

\section{Conclusiones}

A efectos de profundizar los resultados que se presentan del trabajo investigativo, se hace énfasis a una reflexión sobre los siguientes aspectos:

Con respecto a la normativa existente de recaudación de los contribuyentes del Departamento Financiero del Gobierno Autónomo Descentralizado Municipal del Cantón de Jipijapa, es preocupante, ya que se encontró que la ordenanza municipal que contiene el orgánico funcional de la Municipalidad del Cantón de Jipijapa data del año 1999 y en su artículo $N^{\circ} 28$ detalla las funciones y actividades de la Dirección financiera, con respecto a la administración tributaria señala textualmente en su enciso 17: "dirigir y ejecutar la administración tributaria municipal, de conformidad con la ley de Régimen Municipal, las leyes tributarias específicas, las ordenanzas y demás normas y procedimientos legales y técnicos vigentes sobre la materia". Sin embargo, las ordenanzas municipales y las pocas normas que existen sobre recaudación de ingresos no están actualizados. Este nuevo modelo de administración tributaria corregirá estos aspectos ya que establecerá una normativa moderna y ágil.

Con respecto al proceso actual de recaudación de ingresos de los contribuyentes, los ejecuta el Área de Tesorería Municipal perteneciente a la Dirección Financiera, cuyas funciones y actividades están contenidas en la ordenanza municipal en el artículo $N^{\circ} 23$, que data del año 1999. Al respecto se considera que es importante que se elabore los procesos o protocolos de recaudación de ingresos de los contribuyentes el mismo que deberá ser administrado por el nuevo modelo de administración tributaria propuesto para la Municipalidad del Cantón de Jipijapa.

La aplicación de los procesos técnicos administrativos está sujeta a la modernización permanente. La tecnología, la ordenanza legal, la capacitación 
permanente del servidor público es necesaria para fomentar un conglomerado institucional orientado a cumplir con la misión y visión institucional. Por lo tanto, es necesario que el ambiente de trabajo sea el adecuado, la infraestructura física del departamento de tesorería y de toda la institución que debe considerarse en el mediano plazo como una prioridad institucional.

El Gobierno Municipal tiene la obligatoriedad de aplicar las leyes y procedimientos normativos de las ordenanzas. Se debe de aplicar el cobro de impuestos, tasas y contribuciones especiales, para mejorar los ingresos del Gobierno Municipal y sus actividades en beneficio de la colectividad, con ello se reduce la cartera vencida de los contribuyentes, por lo que es necesario que la Municipalidad realice motivaciones publicitarias a la comunidad para que cancelen sus impuestos a efectos de ir generando conciencia tributaria en sus ciudadanos.

\section{Referencias bibliográficas}

Asamblea Nacional del Ecuador (2008). Constitución de la República del Ecuador. Montecristi.

Bird, R. (2003). Taxation in Latin America: Reflections on Sustainability and the Balance between Equity and Efficiency, J.L. Rotman School of Management, University of Toronto, International Tax Program Papers 0306.

Brewer, L. y González, F. (2005). Ley Orgánica del Poder Público Municipal. Colección Textos Legislativos No 34. 2da. ed. Venezuela: Editorial Jurídica Venezolana.

CEPAL (2010). La tributación directa en América Latina y los desafíos a la imposición sobre la Renta. Santiago de Chile: CEPAL.

Cornia, G. A., Gómez, S.J. y Martorano, B. (2011). New fiscal pact, tax policy changes and income inequality: Latin America during the last decade". América Latina: UNU-WIDER WP.

Diez, M. M. (1997). Manual de Derecho Administrativo. Buenos Aires: Plus Ultra.

Fjeldstad, O.H., Katera, L., Ngalewa, E. (2009). Outsourcing revenue collection to private agents: experiences from local government authorities in Tanzania. REPOA Special Paper No. 28-2009. Research on Poverty Alleviation: Dar es Salaam.

Guerrero, O. (2001). Nuevos Modelos de Gestión Pública. Revista digital universitaria, Vol. 2, N³.

Jenkins, G. P. (1995). Tax Reform: Lessons Learned. Development Discussion Paper, 281.

Lora, E. (2007). The State of State reform in Latin America. Stanford: Stanford University Press.

Mahon, J. (2004). Causes of tax reform in Latin America, 1977-1995. Latin 


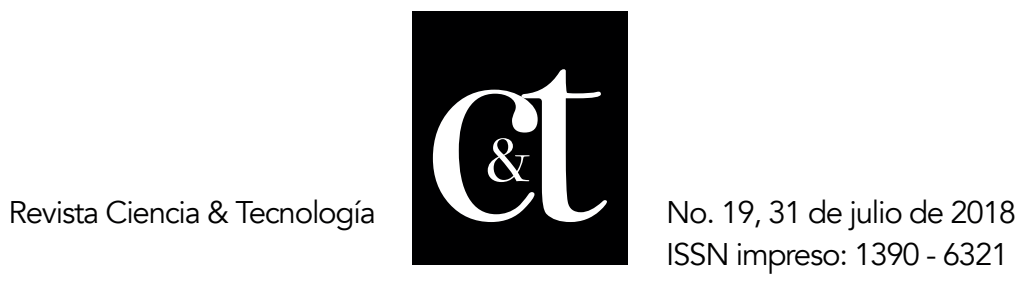

American Research Review, 39(1), 3-30.

Secretaría Nacional de Planificación y Desarrollo - SENPLADES (2017). Plan Nacional de Desarrollo Toda una Vida 2017- 2021. Quito. 